\section{Overshadowing in the discrimination of successive compound stimuli*}

\author{
G. WILLIAM FARTHING \\ University of Maine, Orono, Maine 04473
}

Pigeons were trained on a free-operant, go/no-go discrimination in which $\mathrm{S}^{+}$ (variable-interval reinforcement) was a line-color compound produced by rapidly alternating the separate line and color elements on the response key in a 0.8 -sec cycle. For Group 1, S- (extinction) was a steady disk of light the same color as the $\mathrm{S}+$ compound, whereas for Group $2 \mathrm{~S}-$ was a different color. Group 3 received nondifferential training with $\mathrm{S}+$ only. Subsequently, line-tilt generalization gradients were significantly steeper in Group 1 than in either Group 2 or Group 3. Also, in the test, relative generalization from the line-color compound to the line element alone was significantly greater in Group 1 than in Group 3

Overshadowing may be defined as the observation that, in learning a discrimination, an element of a compound stimulus acquires less control over the organism's behavior if the reinforced $(\mathrm{S}+)$ and nonreinforced (S-) stimuli differ on two or more dimensions than if they differ on only one dimension. For example, Newman \& Baron (1965) trained pigeons to discriminate a compound $\mathrm{S}+$ consisting of a white vertical line superimposed on a green background from an Swhich was either green for one group or red for another group. Thus, the first group could learn the discrimination only on the basis of the presence or absence of the vertical line, whereas for the second group, both line presence-absence and background color were relevant. In a subsequent generalization test on the line-tilt continuum, the gradients were significantly steeper for the first group than for the second group, indicating that the first group had learned more about (or "attended to") the vertical nature of the line than had the second group. One could say that in the second group the dimension of background color "overshadowed" the line-tilt dimension.

The purpose of the present study was to replicate and extend the earlier study by Newman \& Baron (1965) on overshadowing, using a new method for producing the compound stimuli. In the previous studies which employed line-color compounds, the

*This experiment represents part of a dissertation submitted by the author to the Graduate School of the University of Missouri, Columbia, in partial fulfillment of the requirements for the $\mathrm{PhD}$ degree (August 1969). The research was supported by a USPHS predoctoral research fellowship (MH37745) awarded to the author and by a grant from the National Institute of Mental Health (MH12120) to Eliot Hearst. Preparation of this article was supported by a NIMH grant (MH18290) to the author. compounds were produced by colored background. In the present study, the white line (on a black background) was rapidly alternated with the colored disk. Thus, the line element appeared by itself on the key for $0.4 \mathrm{sec}$, followed by the color element for $0.4 \mathrm{sec}$, followed by the line again, etc. This new method of presenting the stimuli is termed a successive compound, in contrast to the simultaneous compounds used in earlier studies.

In the present study, three groups of pigeons were trained to peck at $\mathrm{S}+$, a line-color successive compound reinforcement. In the successive, go/no-go discrimination, S(extinction) was a disk of colored light the same as the $\mathrm{S}+$ color (C1) for Group 1, but for Group $2 \mathrm{~S}$ - was a different color (C2). Group 3 was given nondifferential training with $\mathrm{S}+$ only. Subsequently, the birds were given line-tilt generalization tests in extinction, with the various line tilts presented sometimes in the line-color compounds and sometimes separately. It was predicted that (1) Group 1, trained with line presence-absence as the only relevant cue, would have steeper line-tilt generalization gradients than would Group 2, for which line presence-absence was a redundant cue, or Group 3, which was given nondifferential training, and (2) the response rate (and relative generalization) to the vertical line element alone would be higher in Group 1 than in Groups 2 and 3.

$$
\text { SUBJECTS }
$$

Eighteen experimentally naive female White Carneaux pigeons (5-8 $( \pm 10 \mathrm{~g})$ of their free-feeding body weights.

\section{APPARATUS} Valley Electronics (Model 1519) superimposing the white line on the ( $0 \mathrm{deg} / \mathrm{CI})$, for variable-interval food years old) were maintained at $75 \%$

The birds were trained in a Lehigh pigeon test chamber, in which the transparent plastic key was mounted behind a 25.4-mm-diam circular opening about $254 \mathrm{~mm}$ above the floor, in the center of the intelligence panel.

An in-line readout projector (Foringer No. 1228-10, with GE 44 lamps) could transilluminate the key with a $4 \times 25 \mathrm{~mm}$ white line on a black background and with red or green light. The line could be projected at four different orientations: 0 deg (vertical) and rotated clockwise by $22.5,45$, or $67.5 \mathrm{deg}$. Successive line-color compounds were produced by presenting the vertical line in rapid alternation with either the red or green color. Each line-color cycle was $0.8 \mathrm{sec}$ in duration, each element being on the key for $0.4 \mathrm{sec}$, followed immediately by the other element for $0.4 \mathrm{sec}$, etc., in a repeating sequence.

Variable-interval food reinforcement was programmed by means of two tape timers which ran concurrently. Reinforcements set up on Tape 1 could be collected only by pecks striking the key when the line was on the key, whereas reinforcements set up on Tape 2 could be collected only by pecks striking the key while the color was on the key. Both tapes were punched for a VI 2-min schedule; since the tapes ran concurrently, the overall schedule of reinforcement was VI $1 \mathrm{~min}$. The purpose of this two-tape procedure was to reduce possible correlations between response rate and reinforcement frequency in the two elements of the compound, thus helping to equalize response rates to the two elements. Reinforcers consisted of $4-\mathrm{sec}$ access to mixed grain.

A dim houselight was mounted $60 \mathrm{~mm}$ above the response key. External noises were masked by a white noise and an air blower in the test chamber, which produced a noise level of about $84 \mathrm{~dB}$ SPL at $10 \mathrm{~cm}$ in front of the response key.

\section{PROCEDURE}

Stimuli

Reinforcement was available only for pecking at $S+$, the $0-\mathrm{deg} / \mathrm{C} 1$ successive compound. For three of the six birds in each group $\mathrm{C} 1$ was red, whereas for the other three birds $\mathrm{Cl}$ was green. In $\mathrm{S}-$ periods, the key was transilluminated continuously by $\mathrm{C} 1$ or $\mathrm{C} 2$ for Groups 1 and 2 , respectively. Preliminary Training

All birds were initially trained to peck the 0-deg/C1 compound on the key by the method of successive approximations, and then given 30 continuous reinforcements (CRF) per day for 3 consecutive days. The houselight was on during shaping and 


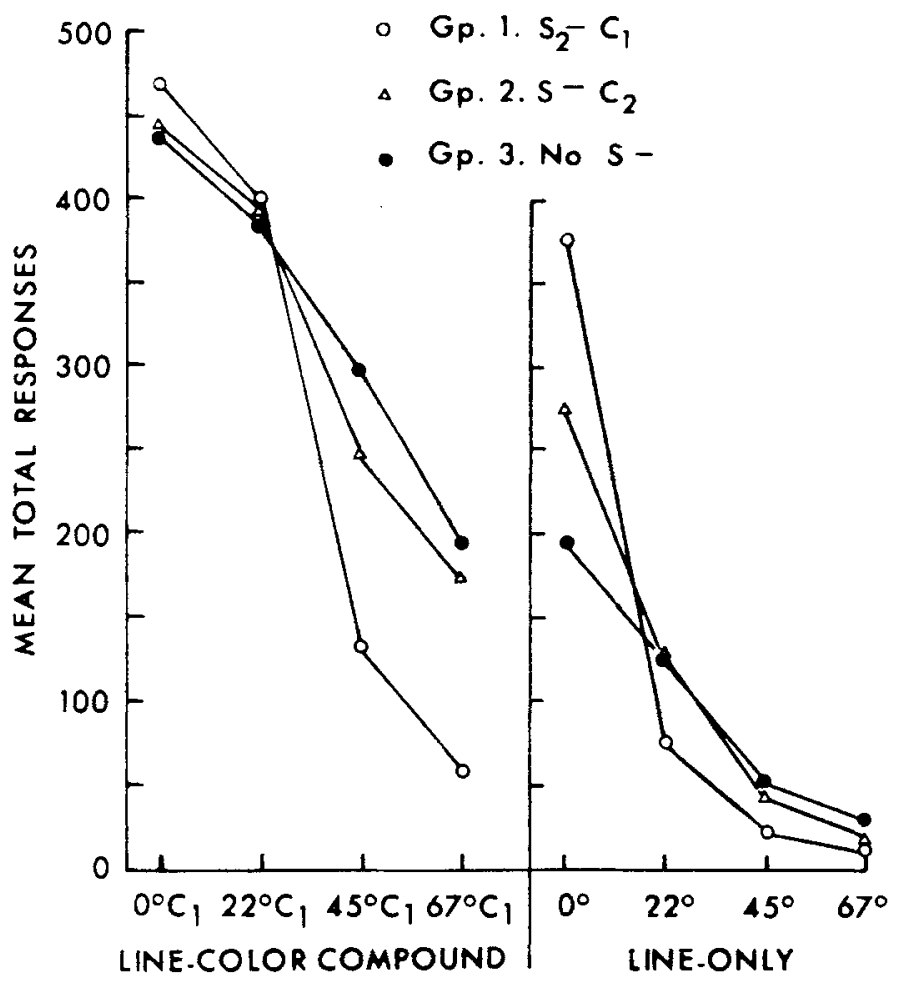

Fig. 1. Mean absolute generalization gradients. The 0 -deg/C1 successive compound was $\mathrm{S}+$ for all of the groups.

the first $30 \mathrm{CRF}$, but it was gradually faded out during the second CRF session. The houselight was off throughout the third CRF session and for the remainder of the experiment. Variable-Interval Training

After preliminary training, all birds were given 15 sessions of training with pecks at $0 \mathrm{deg} / \mathrm{Cl}$ reinforced on a variable-interval schedule with a mean interval between reinforcements of $1 \mathrm{~min}$ (VI $1 \mathrm{~min}$ ). Group 1 was trained on the discrimination of $\mathrm{S}+0 \mathrm{deg} / \mathrm{Cl}$ vs $\mathrm{S}-\mathrm{C} 1$, and Group 2 was trained on the discrimination $\mathrm{S}+0 \mathrm{deg} / \mathrm{C} 1$ vs $\mathrm{S}-$ C2. Discrimination sessions consisted of a mixture of $30 \mathrm{~S}+$ (VI $1-\mathrm{min}$ ) periods and $30 \mathrm{~S}-$ (extinction) periods, with successive $30-\mathrm{sec}$ stimulus periods separated by 10 -sec blackouts, during which the test chamber was dark and pecks were never reinforced. Group 3 was given nominally nondifferential training with $S+0 \mathrm{deg} / \mathrm{C} 1$ only. For Group 3, $S+$ periods were presented in the same temporal pattern as for Groups 1 and 2 , but Group 3 received $30-\mathrm{sec}$ blackouts instead of $\mathrm{S}-$ periods with an illuminated key. Pecks at the 0 -deg and $\mathrm{C} 1$ elements of the $0-\mathrm{deg} / \mathrm{C} 1$ compound were recorded separately. Generalization Testing

On the day following the last variable-interval session, all birds were given a brief warmup of additional reinforced training (10 $\mathrm{S}+$ periods mixed with either $10 \mathrm{~S}-$ periods, for
Groups 1 and 2 , or 10 extended blackouts, for Group 3 ), followed by a generalization test in extinction. The test consisted of four different line-tilt values, presented in each of two subtests. In the line-only subtest, each line tilt was presented continuously on the key during the test stimulus period $(0,22.5,45$, and $67.5 \mathrm{deg})$. In the line-color compound subtest, each line tilt was presented in a successive compound with C1 $(0 \mathrm{deg} / \mathrm{C} 1$, $22.5 \mathrm{deg} / \mathrm{C} 1,45 \mathrm{deg} / \mathrm{C} 1$, and $67.5 \mathrm{deg} / \mathrm{C} 1$ ). The eight test stimuli were presented once in each of 12 randomized blocks. Six different test stimulus sequences were used, with a different sequence fo;each $S$ in each group. The E recorded the number of keypecks during each $30-\sec$ test stimulus period. During testing, stimulus periods were separated by 10 -sec blackouts, as during variable-interval training. RESULTS

\section{Variable-Interval Training}

In the 15 th discrimination session, the discrimination ratio ( $\mathrm{S}-$ responses divided by $\mathrm{S}+$ responses) averaged 0.029 for Group 1 and 0.002 for Group $2(\mathrm{U}=1.5, \mathrm{p}<.01$; all $\mathrm{U}$ tests are two-tailed). Over all 15 sessions of discrimination training, Group 1 averaged 1,295 total errors (pecks at $\mathrm{S}-$ ), whereas Group 2 averaged only 102 total errors $(U=0, p<.01)$. Thus, the discrimination with both color and line presence-absence relevant (Group 2) was considerably easier than the discrimination with only line presence-absence relevant (Group 1).

In the 15th training session, the overall response rates to $\mathrm{S}+$ averaged $102.1,98.7$, and 84.0 per minute forGroups 1,2 , and 3 , respectively; the groups did not differ significantly on this measure $(\mathrm{F}<1)$. However, when the response rates to the 0 -deg line element of the $0-\mathrm{deg} / \mathrm{C} 1$ successive compound were considered separately, significant differences between the groups were found. In the 15th session, response rates to the line element averaged 119.4, 101.0, and 85.8 per minute for Groups 1,2 , and 3 , respectively; only the difference between Groups 1 and 3 was significant $(U=3, p<.02)$. The groups did not differ significantly in response rates to the $\mathrm{C} 1$ element in the $0 \cdot \mathrm{deg} / \mathrm{C} 1$ compound. As a measure of the distribution of pecks between the line and color elements of the $0-\operatorname{deg} / \mathrm{C} 1$ compound, the ratio of pecks at the 0-deg element divided by the total number of pecks at the 0-deg/C1 compound was calculated for each bird. In the 15th training session, this ratio averaged $0.559,0.494$, and 0.495 for Groups 1,2 , and 3 , respectively; the difference between Groups 1 and 3 was significant $(\mathrm{U}=5$, $p<.05$ ), and the difference between Groups 1 and 2 approached significance $(U=7, p<.10)$. However, during the test, the groups did not differ significantly in either absolute or relative response rates to the $0-\mathrm{deg}$ element within the $0-\mathrm{deg} / \mathrm{C} 1$ compound.

\section{Generalization Gradients}

Absolute line-tilt generalization gradients, which plot the mean total number of responses to each test stimulus for each group, are shown in Fig. 1. The right panel shows the results of the line-only subtest, and the left panel shows the results of the line-color compounds subtest.

The data for the two subtests were separately analyzed by means of a three-way analysis of variance for repeated measures on one factor. The three factors were (1) the group treatment (i.e., S- was $\mathrm{C} 1, \mathrm{C} 2$, or none), (2) the $\mathrm{C} 1$ color (red or green) for each subgroup, and ( 3 ) the test line tilt, for which there were repeated measures. The Treatment by Line-Tilt interaction was significant for both the line-color compounds subtest $(F=$ 3.72, $\mathrm{df}=6 / 36, \mathrm{p}<.01$ ) and the line-only subtest $(F=5.57, p<.01)$. No other main effects or interactions were significant, except for the significant main effect for line tilt.

A separate variance analysis of the number of test responses to the $0-\mathrm{deg}$ line in the line-only subtest confirmed 
that Group 1 responded significantly more than Group $3(\mathrm{~F}=12.50$, df $=$ $1 / 10, p<.01)$; the differences between Groups 1 vs $2(F=2.03)$ and Groups 2 vs $3(F=1.18)$ were not significant. The same conclusions about group differences in amount of responding to the $0-\mathrm{deg}$ line can be reached using a relative index of responding to $0 \mathrm{deg}$. Total test responses to the 0 -deg line, expressed as a percent of total test responses to $\mathrm{S}+, 0 \mathrm{deg} / \mathrm{C} 1$, averaged $79.4,60.1$, and 46.0 for Groups 1,2 , and 3 , respectively. Again, the difference between Groups 1 and 3 was significant $(F=13.40, p<.01)$, but the differences between Groups 1 vs 2 $(\mathrm{F}=3.19)$ and Groups 2 vs 3 $(F=1.52)$ were not significant.

When generalization gradient slopes are compared for different groups of Ss, it is conventional to use a relative generalization measure, which permits each $S$ to contribute equally to the group average gradient, even though the Ss may differ widely in their actual number of test responses. Figure 2 shows the group mean relative generalization gradients. Within each group, the mean percent of total test responses was calculated for each line orientation, separate calculations being made for each of the two subtests. The Treatment by Line-Tilt interactions were significant for both the line-color compounds subtest $(\mathrm{F}=4.82, \mathrm{p}<.01)$ and the line-only subtest $(F=8.71$, $\mathrm{p}<.01$ ).

Separate variance analyses were used to compare the relative gradients of the different possible pairs of groups. Treatment by Line-Tilt interactions were significant for Groups 1 vs 2 and Groups 1 vs 3 in both the line-color compounds subtest $(\mathrm{F}=3.57, \mathrm{p}<.05$, and $\mathrm{F}=8.22$, $\mathrm{p}<.01$, respectively; both $\mathrm{df}=3 / 24$ ) and the line-only subtest $(\mathrm{Fs}=8.78$ and 15.45 , respectively; both ps $<.01)$. However, the gradients for Groups 2 vs 3 did not differ reliably in either the compound or the line-only subtest $(F s=1.45$ and 1.51 , respectively).

Using the percents of subtest total responses to $0 \mathrm{deg}$ and $0 \mathrm{deg} / \mathrm{C} 1$ as indexes of gradient slopes, relative gradient slopes were steeper in the line-only subtest than in the compounds subtest for all 18 birds in the experiment

\section{DISCUSSION}

The present experiment, which employed the new technique of successive compound stimuli, successfully replicated the overshadowing effect on line-tilt generalization gradients which was obtained in an earlier experiment that employed conventional simultaneous compound stimuli (Newman \& Baron,

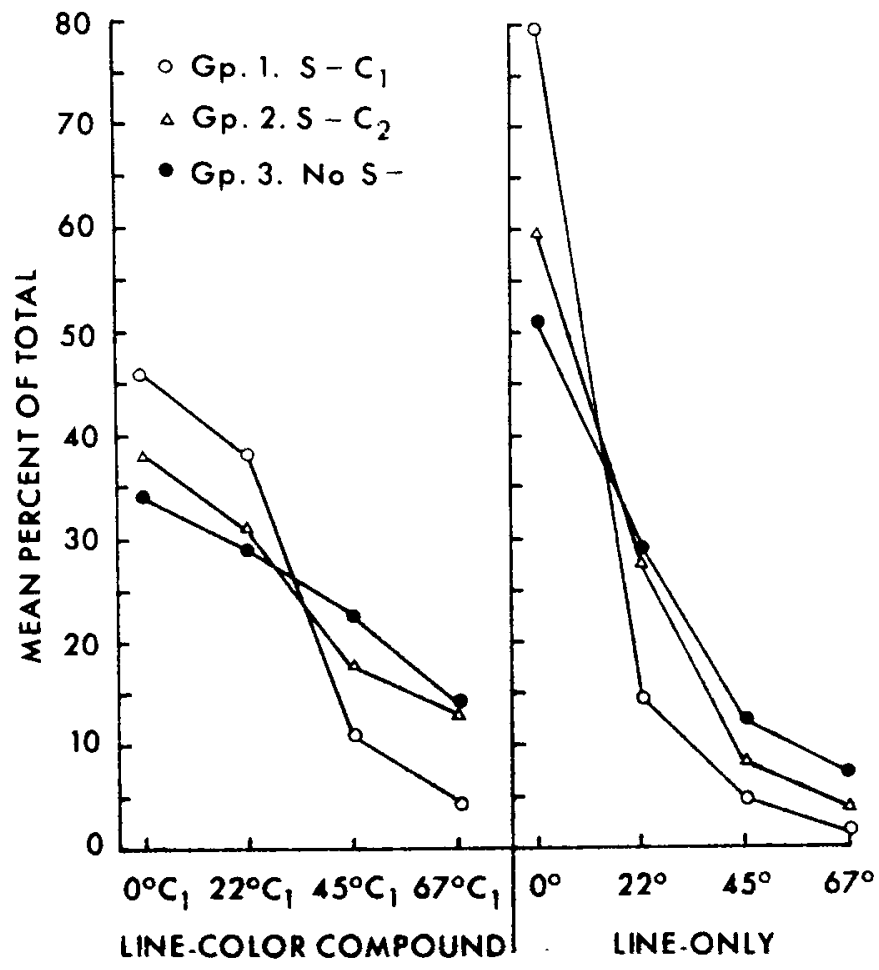

Fig. 2. Mean relative generalization gradients. The 0 -deg/C1 successive compound was $\mathrm{S}+$ for all of the groups. See text for further explanation.

1965). One implication of the present results is that if attentional mechanisms are involved in the overshadowing effect, then apparently the Ss did not, or could not, switch attention from the color dimension to the line-tilt dimension at a high enough rate to insure maximum attention to both dimensions; otherwise, it would seem that Group 2, trained with both color and line presence-absence relevant, would have had line-tilt gradients as steep as Group 1's gradients, which was not the case.

It was predicted that Group 1, trained with only line presence-absence relevant, would peck more at the vertical line element alone than would either Group 2 or Group 3. This prediction was partially confirmed in that Group 1 pecked at the line element significantly more than did Group 3, but the difference between Groups 1 and 2 was not significant. The same differences between the groups were obtained when generalization from the $0-\operatorname{deg} / \mathrm{C} 1$ compound to the 0-deg element alone was calculated as a relative percent generalization score. These data are best interpreted as showing that the color element of the $0-\mathrm{deg} / \mathrm{C} 1$ compound controlled pecking more in Group 3 than in Group 1, since the removal of the color element in presenting the 0 -deg line element alone resulted in a greater generalization decrement in Group 3 than in Group 1. This result makes sense, because the color cue was constant and irrelevant in the discrimination for Group 1. It is difficult to draw conclusions about responding to the line element in Group 2, since it was intermediate between the other two groups and not significantly different from either. In any case, it may be worthwhile to note that in a similar experiment which employed simultaneous line-color compounds, Farthing \& Hearst (1970) did not obtain any differences between the groups in responding to the 0 -deg element alone-in fact, most of the Ss made few or no test responses to the 0 -deg element. The successive compounds procedure may be especially useful in experiments which need to insure that the organism subsequently responds to the less salient element of a compound stimulus.

During discrimination training, Group 1 Ss pecked slightly more at the relevant line element than at the irrelevant color element within the 0 -deg/C1 compound, whereas Groups 2 and 3 pecked at the line and color elements about equally. Much larger effects on the distribution of responses between the elements of a successive compound, under discrimination conditions similar to those of Group 1, have been observed by Farthing (1971) in an experiment which 
employed a 1.9 -sec cycle, rather than a $0.8 \cdot \mathrm{sec}$ cycle, in the successive compound. It will be important in future research on successive compounds to vary the cycle time systematically, in order to determine its effect on both (1) the distribution of pecks between the elements within the successive compound, and
(2) subsequent responding to the elements when they are presented alone for a relatively long period of time (as in the line-only subtest).

\section{REFERENCES}

FARTHING. G. W. Discrimination of compound stimuli involving the presence or absence of a distinctive visual feature. Journal of the Experimental Analysis of Bebavior. 1971, 16, 327-336.

FARTHING. G. W.. \& HEARST, E. Attention in the pigeon: Testing with compounds or elements. Learning \& Motivation, $1970,1,65-78$

NEWMAN, F. L.. \& BARON, M. R Stimulus generalization along the dimension of angularity. Journal of Comparative \& Physiological Psychology, 1965, 60, 59-63. 